\title{
Museología \\ La Casa Museo Antonio Raimondi de San Pedro de Lloc: Gestión, remodelación y propuesta museográfica
}

Lic. Luis Felipe Villacorta Ostolaza1 / Arq. Rodrigo Amorós Figueroa ${ }^{2}$

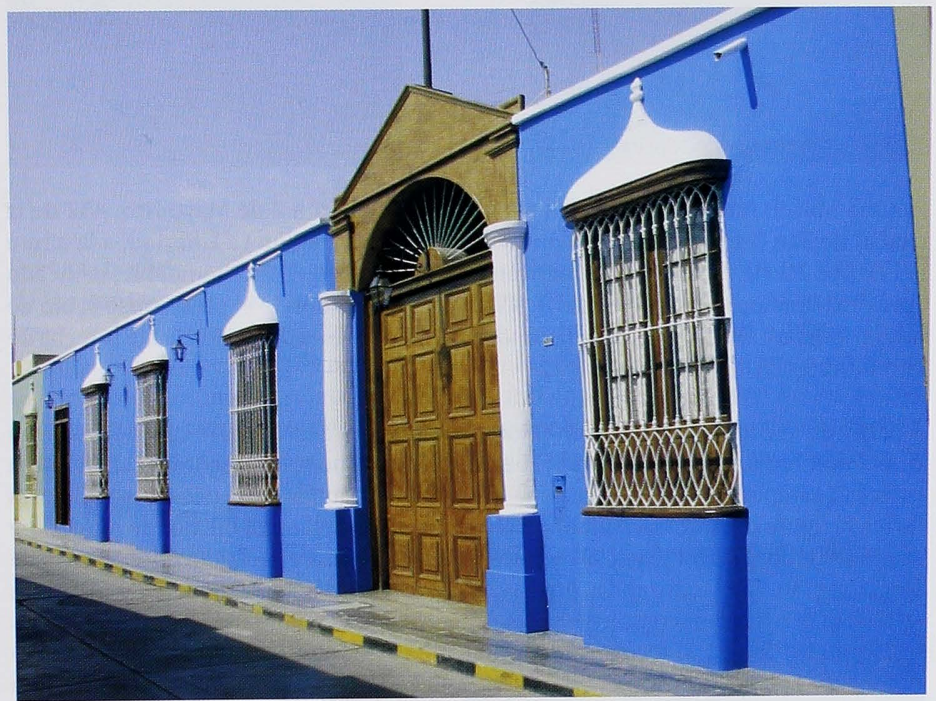

Foto 1 


\section{Resumen}

El presente artículo resume la experiencia de puesta en valor y propuesta museográfica de un monumento histórico declarado patrimonio nacional ubicado en la ciudad de San Pedro de Lloc, provincia de Pacasmayo. El objetivo del proyecto fue transformar este valioso inmueble en un espacio concebido para difundir, de una manera novedosa y pedagógica, el legado y obra científica del naturalista italiano Antonio Raimondi.

A continuación se exponen los antecedentes del proyecto, el contexto en el que se gestó así como las problemáticas y estrategias que se tuvieron implementar a fin de resolver y alcanzar las metas propuestas. De la misma manera se da cuenta de los primeros resultados que la Casa Museo Antonio Raimondi viene asumiendo al servicio de su comunidad y como referente cultural de la localidad. Por último se reseñan los nuevos retos por alcanzar como parte de su futuro desarrollo institucional.

\section{Ubicación y antecedentes}

La Casa Museo Antonio Raimondi está ubicada en el jirón 2 de Mayo Nro. 432 de la ciudad de San Pedro de Lloc, provincia de Pacasmayo, región La Libertad, a la altura del Km. 652 de la carretera Panamericana Norte (ver foto 1). Este inmueble, edificado aproximadamente a mediados del S. XVIII, fue el lugar donde el prestigioso sabio de origen italiano, Antonio Raimondi, pasó los últimos meses de su vida hasta la fecha de su muerte, el 26 de octubre de 1890.

A partir de ese instante la tradición local comenzó a recordar esta casona solariega con el nombre de "Casa Raimondi", perennizando espontáneamente en la memoria colectiva sampedrana la circunstancia histórica de la muerte del naturalista. De esta forma la figura de Antonio Raimondi, representada en el inmueble donde murió, fue asumida como un valor especial de la tradición histórica de la ciudad de San Pedro de Lloc, que se fue afianzando gracias a la celebración sistemática de distintas ceremonias cívicas así como el develamiento de placas recordatorias y monumentos que lo recuerdan en varias partes de la ciudad. Esta etapa de la historia de la casona tiene como punto culminante su declaratoria como monumento histórico gracias a una ley promulgada durante el gobierno del Presidente Manuel Prado Ugarteche ${ }^{3}$.

La suma de todas estas circunstancias, y el anhelo creciente entre el sector amante de la historia de la ciudad de San Pedro de Lloc liderado por el señor Jorge Ramírez Arrigoni y la Asociación Cultural Cupisnique ${ }^{4}$, motivó que a mediados de la década de los años ochenta del siglo pasado, la casona fuese expropiada a favor de la Municipalidad Provincial de Pacasmayo. Esta gestión se realizó gracias a la iniciativa del alcalde de aquel entonces, Sr. Virgilio Purizaga, y tuvo el mérito de rescatar el inmueble del estado ruinoso en el que se encontraba la mayor parte de su infraestructura (ver fotos 2 y 3 ).

Ley Nro. 9385 del 27 de septiembre de 1941

Sr. Fredy Moncada, comunicación personal. 


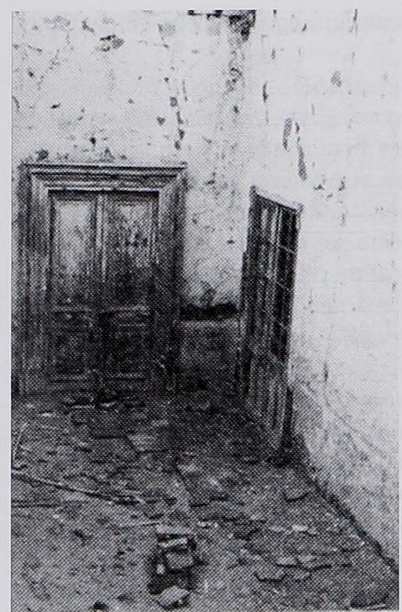

Foto 2

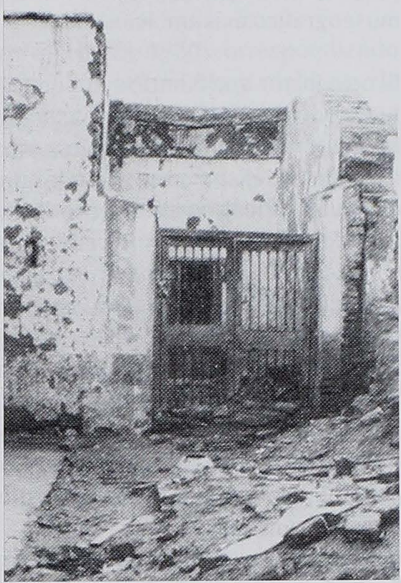

Foto 3

Durante la gestión de Purizaga, y gracias a un fondo de la Corporación de Desarrollo de la Libertad, se realizó la restauración integral de todo lo que se conservaba del inmueble ${ }^{5}$. El propósito de esta acción fue la de transformar el edificio en un verdadero monumento dedicado a perennizar la obra del naturalista más importante del Perú republicano. La remodelación consistió en la refacción total de los muros, conservando su factura tradicional en tapia y quincha. También se habilitaron techos, puertas y ventanas nuevas, imitando aquellas originales pero cuyo estado de conservación hacía imposible su recuperación.

De esta manera, desde su inauguración como "Casa Museo Antonio Raimondi” el año 1989 , esta hermosa casona fue puesta al servicio de la cultura y la educación de la ciudad de San Pedro de Lloc y a la vez en santuario que honra la memoria del sabio italiano (foto 4). A pesar de esta loable iniciativa (acompañada de una inversión de recursos considerables para su tiempo), el proyecto no alcanzó el brillo planificado. Dos circunstancias hicieron que este propósito no se desarrolle en todo su potencial: la primera causa fue la trágica muerte del alcalde Virgilio Purizaga ${ }^{6}$. Ello privó al

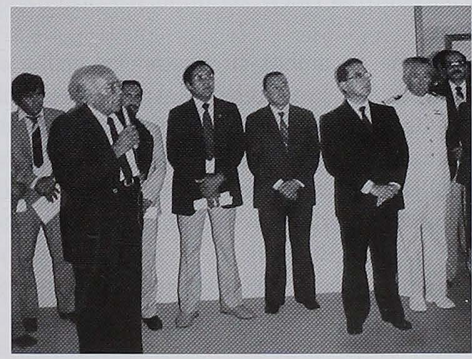

Foto 4

Cabe indicar que para esta época buena parte del área posterior de la "Casa Raimondi", había sido vendida por sus últimos propietarios al Club San Pedro de Lloc, colindante con este inmueble.

El alcalde Virgilio Purizaga fue asesinado en la ciudad de Chepen poco tiempo después de la inauguración de las obras de restauración de la casona. Su muerte fue atribuida a Sendero Luminoso. 
proyecto de su principal gestor e impidió que se continúe con un acondicionamiento museográfico más ambicioso?

El otro factor que contribuyó a que la Casa Museo no asumiera a cabalidad su misión fue la poca importancia que las sucesivas gestiones municipales le dieron al proyecto, lo que terminó por desvirtuar su propósito inicial: rememorar y difundir la obra del naturalista italiano entre todos los jóvenes de la región. Así, la casona pasó a ser lugar de realización de cuanto evento "cultural" o "académico" se pudiera imaginar, sin una agenda de actividades previamente planificada ni una dirección centralizada. Ello vino acompañado de una total desatención en el mantenimiento del edificio, lo que perjudicó los avances logrados por el alcalde Purizaga.

A pesar de todas estas circunstancias negativas, la Casa Museo Antonio Raimondi continuaba siendo el referente cultural más importante del valle bajo del río Jequetepeque $^{8}$. Su sola presencia convocaba al público, particularmente escolar, quienes acudían a conocer el lugar donde de murió el sabio italiano. Con seguridad, este público debió culminar su visita sin satisfacer plenamente su curiosidad sobre este personaje, ya que la "Casa Museo" no contaba con ningún tipo de acondicionamiento o recurso museográfico relevante que permitiera informarse de forma fidedigna sobre Raimondi y la importancia de su obra para el Perú.

Este hecho expone ante nosotros dos circunstancias particulares de la relación museo-público en nuestro medio (y que se acentúa en la mayoría de regiones del país): La primera es la confirmación de la existencia de un público ávido de espacios u ofertas culturales, a pesar de que éstos no cumplen estándares mínimos, tanto expositivos como de servicios conexos. Ello hace que este sector soslaye las deficiencias evidentes de estas "exposiciones" o "espacios culturales locales", lo que es la manifestación de un nivel de exigencia no desarrollado.

La segunda variable es la facilidad con la que un espacio dedicado a la cultura, como el caso de la Casa Museo Antonio Raimondi, adquiere una gran relevancia o posicionamiento en la idiosincrasia popular como referente cultural de la localidad (San Pedro de Lloc).

La suma de ambas circunstancias arriba expuestas, vistas desde una perspectiva positiva, son la expresión del gran potencial de los espacios culturales en provincias, donde haciendas, puertos, estaciones de tren, casonas, calles, iglesias y plazas son portadoras de valores históricos relevantes que pueden ser desarrollados como catalizadores sociales, en beneficio del desarrollo cultural y económico de sus propias localidades.

La inauguración de 1989 tuvo como propósito principal presentar la culminación de las obras de restauración del edificio. La exposición provisional de aquella época se restringió a la ambientación de época de la habitación donde murió Raimondi así como a una muestra de objetos diversos y un mapa de sus viajes en el "salón de usos múltiples".

No existe ningún museo formalizado de cualquier tipo en toda la cuenca baja del valle de Jequetepeque a pesar de la rica trayectoria arqueológica, cultural, histórica y natural de esta región. Esta situación es bastante particular teniendo en cuenta además la existencia de importantes ciudades como en el valle y el mismo San Pedro de Lloc, Guadalupe, Pacasmayo, Chepén, Jequetepeque o San José. 


\section{La Casona: valores monumentales y propietarios}

Esta antigua casona fue edificada aproximadamente en el año 1750, correspondiendo al típico estilo neoclásico, destacando por sus amplios ventanales y molduras de influencia morisca adornadas con las tradicionales rejas de fierro forjado de la costa norte del Perú. Es de notar su pórtico de cedro coronado por un macizo triangular de la misma madera, cuya composición semeja la fachada de un templo masón. Este arreglo aparece flanqueado por dos columnatas estriadas de color blanco que hacen las veces de soporte del macizo triangular del pórtico (ver foto 1).

En cuanto a su distribución, el inmueble reproduce el típico trazado de las casonas solariegas norteñas. El primer espacio al interior de la casona es el zaguán, el que luego de cruzar la tradicional reja, conduce al visitante al patio donde destaca el antiguo pozo de agua ${ }^{9}$ y el busto del sabio ${ }^{10}$. Este espacio abierto organiza la distribución de los ambientes principales de esta parte de la casona, entre ellos el ambiente que constituye el atractivo principal del edificio: la habitación donde murió Antonio Raimondi.

Ya en el patio, se puede distinguir entre las partes originales del edificio restaurado (fachada y flanco izquierdo) y aquella completamente nueva (sala de usos múltiples). Este último ambiente se edificó con mampostería de ladrillo a fin de restituir, en composición semejante a su aspecto original, el aspecto integral del patio de la casona. Este agregado moderno se explica en razón de la destrucción ocasionada por el tiempo, y posterior venta de un tercio del inmueble original al vecino club social San Pedro de Lloc. Esta es la causa por la que los ambientes domésticos principales de la antigua casona, incluyendo cocina, dormitorios, sala y patio interior ya no existen, ya que el terreno que antes ocupaban fue incorporado como parte del predio propiedad del mencionado club".

A la fecha sólo se conservan las habitaciones laterales del edificio, a los que se agrega una pequeña porción de lo que fue la huerta de la casa, espacio dedicado a la siembra de hortalizas así como para la guarda de las cabalgaduras. Como todos los espacios de su tipo, la huerta colinda con la calle posterior, haciendo las veces de puerta de servicio.

En cuanto a otros detalles históricos del monumento, se sabe que originalmente correspondió a la casa solariega de la familia de Don Vicente Goyburu, nacido en el País Vasco y subdelegado de la Marina Real en el Puerto de Pacasmayo. En algún momento a mediados del S. XIX el inmueble pasó a ser propiedad del médico italiano don Alessandro Arrigoni, amigo íntimo de Antonio Raimondi desde sus años juveniles en Milán. Arrigoni fue uno de los vecinos más notables de San Pedro de Lloc y se dedicó con relativo éxito a la actividad comercial. Justamente durante el tiempo que la casona le perteneció, Arrigoni la acondicionó como posada para viajeros, siendo aún recordada entre algunos vecinos la antigua inscripción en su frontis: "Hotel Perú"

Hoy clausurado.

Este busto fue develado en 1990 como parte de las celebraciones por el centenario de la muerte de Raimondi. Originalmente se ubicó en medio del patio, sobre una base de forma piramidal (ver foto Nro. en este articulo).

En la actualidad este espacio es usado como un gran salón de actos, no quedando ninguna evidencia del trazado original. 
Luego de la mudanza de Arrigoni a Lima, ocurrida tras la muerte del sabio, la casona pasó por manos de diversos propietarios, como la familia de Don José Salcedo, del prestigioso juez cajamarquino Antenor Guerra García y luego a la familia Suárez, prácticamente sus últimos inquilinos ${ }^{12}$.

\section{El proyecto y sus problemáticas}

En junio del año 2003 el Museo Raimondi de Lima ${ }^{13}$ recibió la visita del Sr. Fredy Moncada, regidor de patrimonio histórico y monumental de la ciudad de San Pedro de Lloc a fin de interesarnos en participar de una iniciativa que rompiera el letargo y estado de virtual abandono en el que se encontraba la casona.

Debido a la comunión de ideales e intereses, se estableció un plan de acción que contempló dos áreas de trabajo: la evaluación del estado físico-legal de la casona y el desarrollo de un anteproyecto museográfico. Sobre la base de la información acopiada, se estableció un presupuesto referencial de la inversión que demandó esta iniciativa.

Como resultado de esta etapa de nuestro trabajo, se llegó a las siguientes conclusiones: el proyecto de acondicionamiento integral de la casona debería

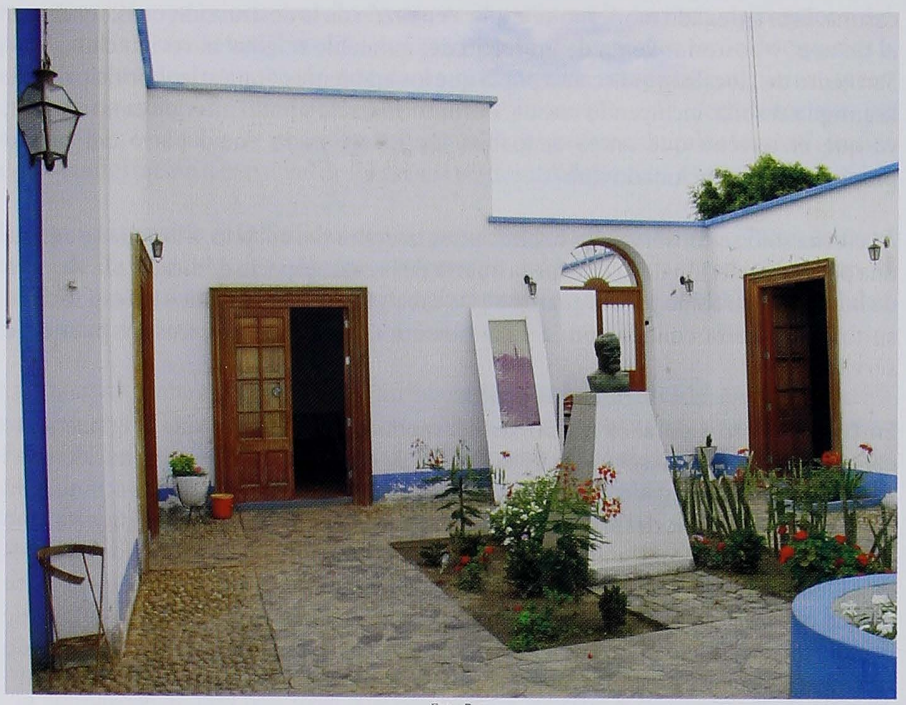

Foto 5

Moncada, 2002.

Institución privada promovida por la Asociación Educacional Antonio Raimondi, ente representativo de la colectividad italiana afincada en el Perú y responsable del tradicional Colegio Italiano Antonio Raimondi de Lima. Este museo fue fundado el año 1981 como parte de su política institucional de conservar, investigar y difundir la obra de Antonio Raimondi en el Perú. 
desarrollarse en dos etapas, dedicándose inicialmente a intervenir en los espacios abiertos al público (pe. cuarto de Raimondi, sala permanente, sala temporal, oficina de turismo local y patio principal), y dejar para un segundo momento el resto de ambientes concebidos en la propuesta integral para el edificio (pe. oficinas administrativas, depósitos, sala de conferencia, equipamientos, etc.).

El otro aspecto que se concluyó fue que el proyecto debería tener un diseño novedoso y participativo que favoreciera la captación de recursos alternos a los dispuestos por la municipalidad y la Asociación Educacional Antonio Raimondi de Lima ${ }^{14}$, ya que la demanda financiera no era poca.

El estado que presentaba la Casa Museo Antonio Raimondi en este momento ега poco alentadora. En cuanto a su exposición se debe mencionar que no existía ninguna propuesta museográfica que ilustre al visitante sobre la importancia del inmueble ni la relevancia del personaje a quien le debe su nombre. La apariencia y estado de conservación de la infraestructura, a pesar de los trabajos de restauración de finales de los ochenta, era mala. La mayoría de ambientes no tenía un piso que pudiera ser considerado "utilizable", la totalidad de las conexiones eléctricas eran inservibles y la pintura de mala calidad. Asimismo las puertas y ventanas no habían recibido ningún tipo de mantenimiento, por lo que se encontraban en malas condiciones. El "salón de usos múltiples" no servía como tal, ya que su techo de estructura de tijerales metálicos y calamina lo hacía prácticamente inservible para reuniones masivas por el calor que

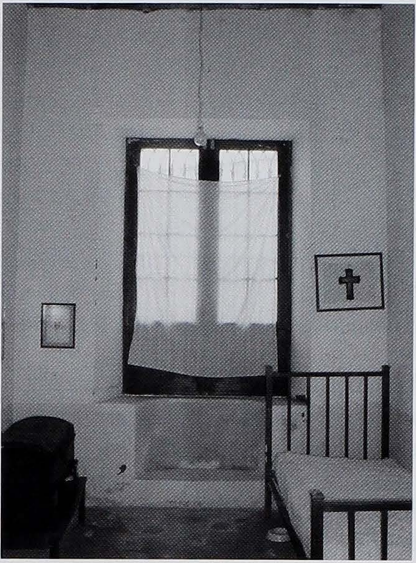

Foto 6

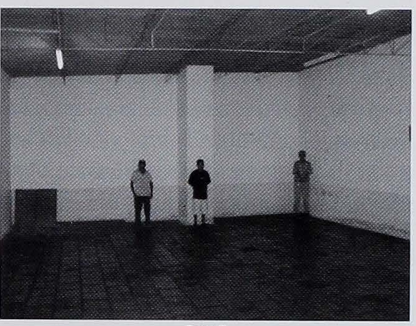

Foto 7

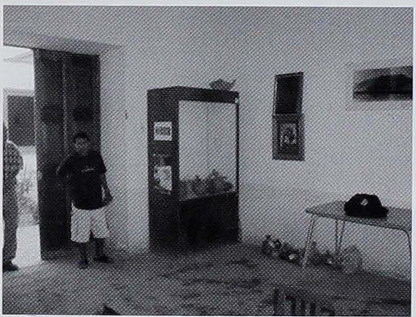

Foto 8 acumulaba en esta soleada región, situación que se agravaba por la escasa altura del techo existente (ver fotos 5, 6, 7 y 8 ).

El primer reto que tuvo que enfrentar el proyecto estuvo en el orden de su infraestructura. Resultado de la evaluación físico-legal del inmueble, se estableció que era necesaria una intervención estructural a fin de consolidar los cimientos. Un 


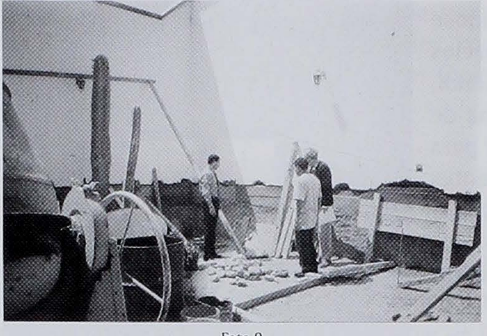

Foto 9

problema relativamente reciente a toda la ciudad había ocasionado este inconveniente: la elevación de la napa freática ${ }^{15}$. Debido a que el edificio era un monumento nacional se requirió la elaboración del expediente técnico de proyecto de intervención ante el Instituto Nacional de Cultura (INC). Este trámite fue aprobado por las instancias respectivas del INC mediante resolución Directoral

Nacional Nro.00131 del 20 de mayo del 2004 luego de seis meses de gestiones.

La consolidación de todos los cimientos de los muros a intervenir en la primera etapa consumieron buena parte de la partida de $S / .22,000.00$ destinados por la municipalidad a este proyecto. Sin embargo, lo que comenzó como una idea difusa, se iba transformando en una grata realidad (ver foto 9).

\section{Los espacios: la asignación de usos, el guión y la museografía}

El nuevo uso de los espacios y el desarrollo museográfico elaborado como parte del diseño del proyecto debió conciliar en su propuesta su adecuación a un espacio físico dado (la casona), la necesidad de incorporar criterios expositivos y de organización elementales para cualquier museo (pe. sala permanente, sala temporal, etc.) así como presentarlo ál público visitante como un espacio de promoción de los distintos tipos de atractivos locales (pe. sostenibilidad y validación social).

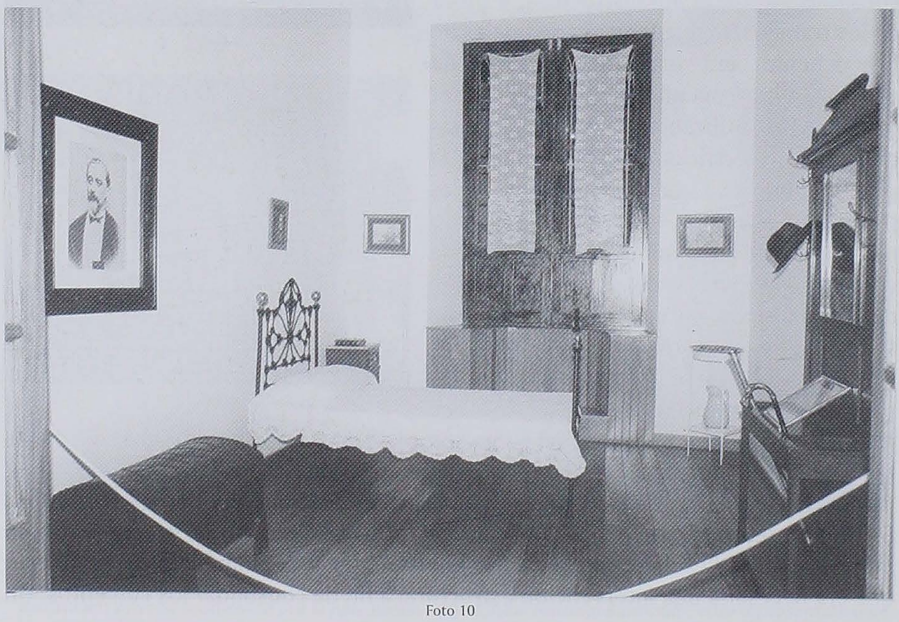

Fenómeno que se ha agudizado en los últimos tiempos debido a los cultivos por inundación de los campos de arroz circundantes a la ciudad. 
Considerando estas premisas se determinó que la exposición permanente ocuparía dos ambientes de la casona: la habitación donde murió Antonio Raimondi y el antiguo salón multiusos, el que pasaría a convertirse en una sala dedicada a mostrar al público visitante la vida y obra del naturalista italiano. Asimismo se estimó conveniente adaptar otro ambiente para que funcione como sala temporal, cumpliendo así con el objetivo de renovar permanentemente las exposiciones y dinamizar la actividad cultural de la casa museo. Por último se decidió implementar la oficina de la dirección, la que tendría por misión el control administrativo de la casa museo (pe. boletaje, estadísticas, relaciones institucionales, etc.), haciendo también las veces de centro de información y promoción turística de los atractivos de la localidad.

Una vez determinado el uso de cada espacio a intervenir se definió el guión de las salas de exposición permanente. En ambos casos se tuvo que afrontar problemáticas distintas. Como la lógica lo indicaba, el diseño de la muestra de la habitación pretendía recrear un escenario similar al de la muerte del naturalista, el que se fundamentaría en la exposición de muebles de época. Desafortunadamente la casa museo sólo contaba con un baúl de propiedad del sabio como único material original susceptible de ser exhibido para el propósito señalado. No se disponía de ningún mobiliario adicional o de época que permitiera una ambientación fidedigna.

La solución a esta situación vino de la mano de los vecinos sampedranos; enterados del problema que se afrontaba, se inició una campaña silente en búsqueda de mobiliario de finales del S. XIX (pe. catre de fierro forjado, lavaderos de losa, visillos ${ }^{16}$, aparadores, etc.). Esta situación tuvo como punto culminante la restitución del piso machihembrado de pino oregón, ya que el original había desaparecido. Aquel que se instaló en este ambiente fue donado gentilmente por un vecino de la ciudad cuya casona había colapsado hace unos años ${ }^{17}$. Esta es sólo una muestra de la identificación que el proyecto iba despertando entre los pobladores de la ciudad. Así, los resultados logrados gracias al apoyo ciudadano fueron auspiciosos si se tiene en cuenta las limitaciones que se afrontaron (ver foto 10 ).

La sala permanente tuvo que ser intervenida debido a su precario estado. Por ello se desmontó el techo de calamina existente, se elevó y uniformizó la altura de los muros del ambiente (4 m. de altura libre), posteriormente se volvió a cubrir con las calaminas originales para culminar con la instalación de un cielo raso que brindara al visitante un acabado y confort acordes con este espacio (ver fotos 11 y 12 ).
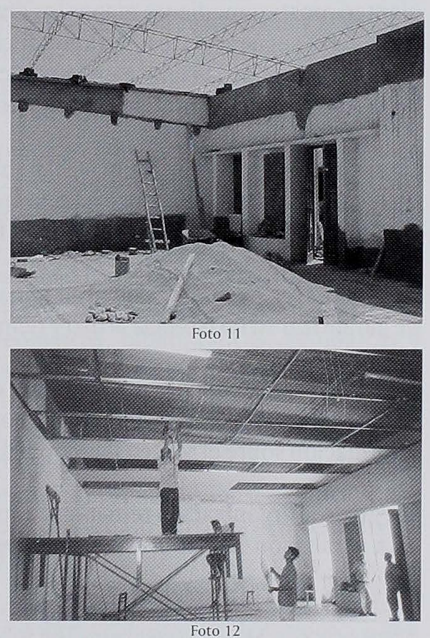

Tradicional cortina hecha a mano (croche) y que se utilizaba para tapar las lunas de los grandes ventanales de las casonas coloniales.

Sr. Jimmy Mejía Barba. 
Un reto aparte fue la materialización del proyecto museográfico de la sala dedicada a la obra del sabio en el Perú. En este caso se asumió la tarea de desarrollar una exposición en un "museo" que carecía de colecciones ${ }^{18}$. La solución a esta problemática vino de la mano de la característica principal del legado documental de Raimondi: el vigor gráfico y diversidad temática de las ilustraciones de su obra. Fue así como se planteó un guión museográfico que presenta de manera cronológica y sintética, la vida de Raimondi y sus distintas facetas científicas. La selección de imágenes tuvo como fundamento el archivo documental del Museo Raimondi de Lima, como de aquellas otras ilustraciones de instituciones y personas naturales que cautelan material del sabio ${ }^{19}$.

El guión museográfico se planteó sobre la base de cinco secuencias que relatarían al público la vida y obra del sabio italiano: presentación, sus viajes y libretas, sus facetas científicas y finalmente el respaldo institucional a la difusión de su obra en el Perú. De esta manera los $107 \mathrm{~m} .^{2}$ de la sala permanente brindarían al público visitante una amplia y completa visión de Antonio Raimondi, contextualizando sus viajes y descubrimientos, creando un nexo entre Italia, sus exploraciones, vida personal, legado científico y ético así como su prestigio social y las instituciones que lo cautelan.

A su vez cada tema se organizó espacialmente, desarrollando diversos aspectos del guión. En la primera secuencia de introducción se creó un nexo entre la Italia que el sabio dejó y el país que lo acogió, teniendo como eje el mapa Perú y fotografías de época de Italia. Asimismo un panel sitúa al público usuario en el contexto histórico de los naturalistas y la imagen de nuestro país en el S. XIX. En la siguiente secuencia se planteó mostrar mediante mapas los diversos viajes que el sabio realizó al interior del Perú. En la secuencia tres, "Raimondi científico", se expone sus descubrimientos en diversas ramas de la ciencia en base a cinco paneles y dos vitrinas que organizan los temas desarrollados: arqueología, geología y minería, fauna, flora y cartografía.

Luego, en la siguiente secuencia, el público puede apreciar diversas investigaciones y publicaciones del sabio, entre ellas la inconclusa versión impresa de su obra "El Perú". Finalmente y pensando en el público infantil, se presentó un libro para niños con hermosas ilustraciones sobre el sabio y sus viajes. La materialización de esta idea fue mediante tres ejemplares de gran tamaño (formato A3); con hojas plastificadas a fin de garantizar su resistencia al uso y tiempo.

El último espacio temático, "Raimondi en el Mundo", pone en evidencia los alcances de su vida y obra a nivel internacional, mostrando la pagina web del museo, información sobre el Museo Raimondi de Lima y el legado documental que cautela.

Luego de la organización temática de las ilustraciones, se planteó como solución para esta exhibición la elaboración de infografías, formato que resalta de manera ágil,

\footnotetext{
${ }^{8}$ Si bien la Casa Museo Antonio Raimondi tiene colecciones de objetos arqueológicos (pe. cerámica, líticos, textiles, etc.), así como paleontológicas (pe. fósiles) y geológicas (minerales), ellas no tienen vinculación directa con Raimondi, ya que no fueron formadas o recogidas por él.

El Museo Raimondi dispone de un "archivo digital" que contiene la mayoría de documentos del sabio existentes en otros archivos. Entre ellos se debe destacar el Museo de Arte de Lima, el Archivo General de la Nación y dos colecciones particulares de Lima.
} 


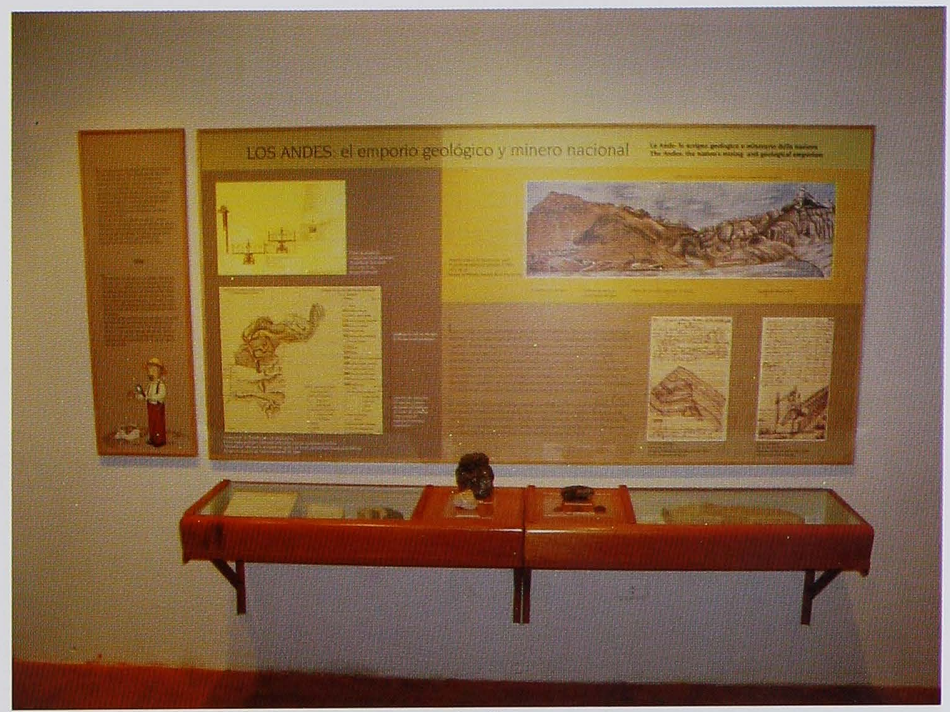

Foto 13

didáctica e individual la idea fuerza de esta exposición: la vida y trabajo científico de Raimondi en el Perú (ver ejemplo de infografi ${ }^{20}$ ). Por su versatilidad, las infografías cumplen a cabalidad con la misión de informar, conciliando además una calidad de impresión que por sus características técnicas, garantizan su resistencia y adecuada conservación en el ambiente de la exposición, incluso ante eventuales daños resultado del vandalismo moderado (pe. pintura, arañazos, etc.) ${ }^{2 T}$.

Por otra parte, el desarrollo de infografías de tamaño estándar ${ }^{22}$, mediante paneles de $2.20 \mathrm{~m}$. x $1.10 \mathrm{~m}$. y $2.20 \mathrm{~m}$. x $1.80 \mathrm{~m}$., optimizaron una adecuada planificación y uso del espacio, simplificando sustancialmente detalles como la iluminación (al homogenizar los requerimientos lumínicos), motivando el diseño de un novedoso sistema de vitrinas fijas a la pared que acompañaban cada infografía. De esta manera se integraron las infografías a la exposición en concordancia temática con las piezas de la colección de la casa museo (pe. arqueológicas, bibliográficas, geológicas y paleontológicas). La ventaja de este sistema es que nos permitió incorporar a la exhibición objetos acondicionados especialmente para tocar y oler (pe. minerales, puntas de fecha de piedra, guano de las islas). Así se dio uso material original de las colecciones de la casa museo que difícilmente hubiesen sido útil de otra manera, contribuyendo a la vez a innovar sustancialmente las propuestas museográficas de la región (pe. estímulo de los sentidos del olfato y tacto como parte de la propuesta de información-aprendizaje del museo ver foto 13).

\footnotetext{
Todas las infografías de la Casa Museo Antonio Raimondi fueron elaboradas por la diseñadora gráfica Berthi Gibaja.

Impresas en alta resolución (1200 dpi) sobre una banda continua a todo color, laminado UV y teniendo como soporte una base de trupan.

Se elaboraron tres infografias de $2.20 \times 1.80$ y once de $2.20 \times 1.10$
} 
Adicionalmente se desarrolló un sistema de paneles complementarios cuyo objetivo era presentar en italiano e inglés la información más relevante detallada en la infografía contigua, facilitando así la promoción de la casa museo como destino para el visitante extranjero (ver foto 13). Como detalle a resaltar, se debe mencionar que este panel sirvió de soporte para presentar las imágenes de un cuento para niños que tiene como guión la vida de Antonio Raimondi ${ }^{23}$. Para ello se caracterizó un personaje que representa al sabio italiano desempeñando distintas facetas de su labor científica (pe. como arqueólogo, descubriendo monumentos prehispánicos; como geólogo, analizando minerales; como viajero, recorriendo el Perú; como etnógrafo, en su relación con los grupos indígenas) ${ }^{24}$.

La combinación de las infografías, el sistema de vitrinas diseñado especialmente para ellas así como los objetos para tocar y oler, garantizan una sala de exposición que privilegia tanto una información ágil y didáctica como la formalización de un guión y diseño museográfico innovador, moderno y de bajo costo, ideal para nuestro medio ${ }^{25}$.

No podía faltar en esta sala sendos espacios que resaltan los descubrimientos más importantes de Antonio Raimondi: la puya y la lito escultura Chavín que hoy llevan su nombre. Estos descubrimientos, símbolos nacionales de nuestra riqueza botánica y patrimonio arqueológico, se pueden apreciar flanqueado el ingreso a este ambiente, el primero en una foto ${ }^{26}$ y el segundo en una hermosa replica de madera ${ }^{27}$.

En cuanto a la dinámica de circulación de la muestra de la sala dedicada a la vida y obra de Raimondi, si bien ésta privilegia un sentido horario (ver plano de sala permanente), su propuesta de guión (una infografía=un tema), permite al visitante sentirse cómodo si decide recorrer libremente el espacio de la exposición. Así mismo no se ha dividido la sala en pequeños subespacios, los únicos tres paneles libres no llegan al techo, creando de esta manera una sensación de amplitud y libertad para que el visitante recorra la sala según el orden y dirección de su interés.

La propuesta de iluminación de la sala partió de la premisa de la necesidad de reemplazar toda la instalación eléctrica existente, debido a su mal estado. Durante las obras de remodelación se tomaron en cuenta las nuevas salidas eléctricas, tanto para la iluminación cenital como para los tomacorrientes. La iluminación se debía resolver de una manera económica, de fácil mantenimiento y con repuestos factibles de adquirir en la localidad. Es así que se propuso un anillo de iluminación suspendido del techo a $3.00 \mathrm{mt}$. de altura. El anillo, realizado en tubo metálico de 1 1/2" soporta rieles de $1.80 \mathrm{mt}$. con 4 reflectores dicroicos cada uno, los mismos que iluminan las infografias con un ángulo de 60 grados, garantizando de esta manera una adecuada

\footnotetext{
Proyecto elaborado por el Museo Raimondi y las profesoras de Escuela Materna del Colegio Italiano Antonio Raimondi de Lima.

El desarrollo y caracterización gráficos de Antonio Raimondi fue elaborada por un equipo de jóvenes artistas gráficos de la Universidad Católica liderados por Ruperto Pérez-Albela Stuart.

El valor de cada infografías es de S/. 400.00 en promedio (Impresión a 1200 dpi en vinil autoadhesivo laminado mate con protección UV pegado sobre trupan de $5 \mathrm{~mm}$. con bastidores de trupan y con listones de madera pegados al perímetro).

Reproducción en back light.

Esta replica fue elaborada por los miembros de la Asociación Cultural Cupisnique y fue puesto en exhibición para la inauguración de las obras de restauración de la casona en 1989.
} 


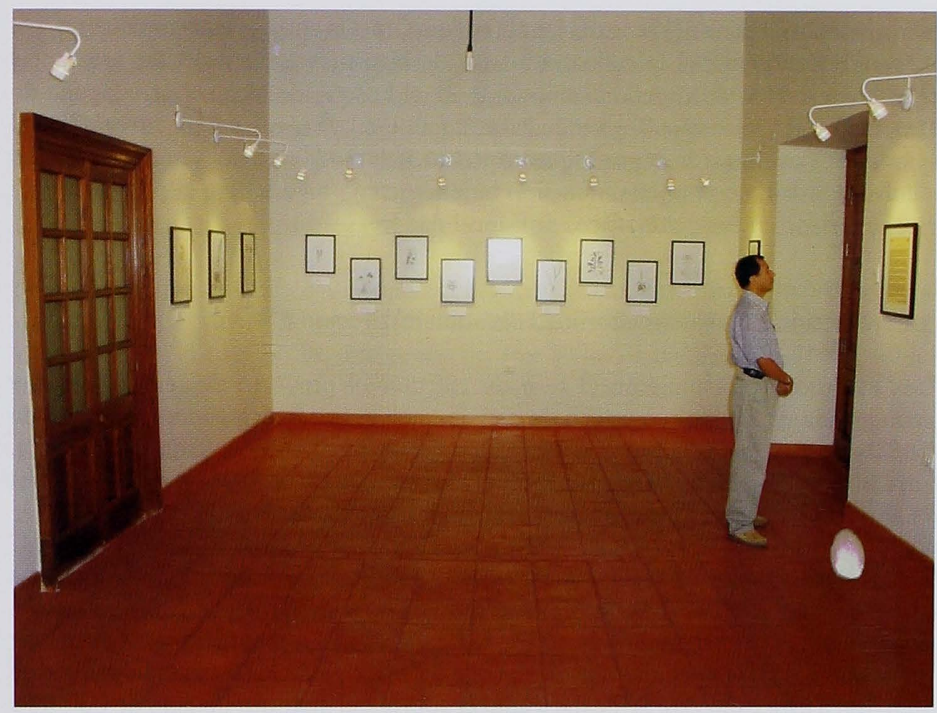

Foto 14

iluminación sin reflejos molestos (ver plano Nro.1). Esta iluminación se complementa con algunos dicroicos puntuales para las vitrinas exentas.

Por otra parte se debe mencionar que el área intervenida en esta etapa del proyecto consideró destinar un ambiente de la casona para su uso como sala temporal. Este espacio asume la misión de darle dinamismo a la actividad cultural de la casa museo, siendo a la vez el espacio natural de exposición para las obras de los artistas, artesanos y demás interesados de la región. Un requisito fundamental a cumplir a fin de otorgarle la mayor versatilidad posible con respecto a formatos, temas y tipos de exposiciones era su independencia con respecto a los demás ambientes de la casa museo abiertos al público. Por fortuna el diseño del edificio favoreció este propósito, ya que la sala temporal, como el resto de ambientes de esta casa solariega, tiene acceso directo e independiente desde el patio principal (ver plano). De esta forma, el día de la inauguración de la "Casa Museo Antonio Raimondi" ${ }^{28}$, se abrió la primera muestra de la sala temporal, la que estuvo dedicada a las acuarelas botánicas pintadas por Antonio Raimondi a lo largo de sus viajes por el Perú ${ }^{29}$ (ver foto 14).

El último espacio a definir fue el ambiente destinado a la administración de la casa museo, el que a la vez cumpliría la labor de oficina de información al turista, sirviendo tanto de guía sobre los atractivos de la localidad como de enlace con los operadores turísticos, hoteles y restaurantes de la provincia. El acondicionamiento de este espacio también hizo uso de las infografias, donde se destaca un mapa con los

\footnotetext{
${ }^{28}$ El acondicionamiento museográfico de la Casa Museo Antonio Raimondi se realizó el sábado 11 de junio del 2005.

${ }^{29}$ Reproducciones de alta calidad.
} 
principales atractivos del valle del Jequetepeque ${ }^{30}$ (pe. la antigua estación de tren $^{31}$, el balneario de Puémape, la culinaria a base de lagartijas (cañanes) ${ }^{32}$, las artesanías típicas como el famoso pellón sampedrano ${ }^{33}$, el bosque de algarrobos y laguna de Cañoncillo, el sitio arqueológico de Pacatnamú, etc.). Esta oficina da cuenta del rol que le toca asumir a la "Casa Museo Antonio Raimondi", no sólo en cuanto a los valores e historia que representa, sino también como medio para la promoción de ricos y variados recursos turísticos de la localidad (ver foto 15).

\section{La provisión de recursos alternos: la gestión institucional ${ }^{34}$}

Dos instituciones asumieron el reto de ejecutar el proyecto de remodelación y acondicionamiento museográfico de este inmueble: La Municipalidad Provincial de Pacasmayo en el ámbito local y la Asociación Educacional Antonio Raimondi de Lima. Sin embargo, se debe indicar que el proyecto convocó a otros actores, institucionales y naturales, nacionales y extranjeros, a fin de alcanzar las metas propuestas.

El criterio fundamental para alcanzar el éxito en estas gestiones fue identificar los intereses comunes que cada una de estas instancias requerían a fin de involucrarse en el proyecto. El primer campo de acción fue convocar a las instituciones italianas de nuestro medio, las que lideradas por el decidido apoyo de la Embajada de Italia, se sumaron a este esfuerzo. Se destaca aquí el aporte del Instituto Italiano de Cultura y de la Asociación de Italianos Residentes en Trujillo.

En el ámbito local se identificó a las instituciones gremiales y empresariales representativas de la región, cuyos objetivos e intereses corporativos tienen una marcada orientación en beneficio de la localidad que los acoge. En ese sentido fue crucial el apoyo recibido de la Junta de Riego Tecnificado del Valle de Jequetepeque así como de Cementos Pacasmayo S.A.A. En el caso de la última empresa, su apoyo fue retribuido por los gestores del proyecto al develar una placa que bautiza con su nombre a la sala temporal de la casa museo. Ello pone en relevancia el reconocimiento público del aporte de esta empresa y a la vez formaliza un vínculo simbólico que hacen viables futuras contribuciones en beneficio de la "Casa Museo".

Por su parte se aprovechó el aporte de instituciones que tienen un marcado interés en la promoción de la historia y los recursos turísticos del país. En ese sentido se debe destacar el patrocinio de Prom Perú y Fundación Telefónica. Ambos entes colaboraron con recursos, capacidades logísticas y su experiencia a fin de alcanzar las metas

\footnotetext{
${ }^{30}$ Cabe indicar que existe una infografía en el zaguán (ingreso) de la casona. Aquí se detalla su historia teniendo en cuenta su historia como monumento histórico y haciendo una semblanza de sus primeros impulsores, el Sr. Jorge Ramírez Arrigoni y el Sr. Virgilio Purizaga Aznarán.

Esta estación de tren ha sido cedida a la Facultad de Arquitectura de la Universidad Católica para desarrollar su proyecto de puesta en valor así como proyectar desde aquí, un plan regulador de recuperación y recuperación del casco urbano de la ciudad, el que posee notables valores históricos y monumentales.

Debido a su afición por el consumo de lagartijas, los sampedranos son popularmente conocidos en la región con el afectuoso mote de "lagartijeros".

Accesorio de las sillas de los caballos de paso.

- Para una adecuada definición de Gestión Institucional y su relación con los museos véase el "Manual para Pequeños Museos" elaborado por el Instituto Goethe de Lima.
} 
logradas. Por último no se puede soslayar el apoyo crucial del pueblo de San Pedro de Lloc, el que se sumó libre y espontáneamente a esta iniciativa, contribuyendo a resolver con su esfuerzo todos los pequeños e innumerables detalles que han hecho de esta obra un nuevo orgullo regional. Esta manifestación de colaboración en esta etapa del proyecto sirvió para comprobar la importancia de la casa museo en la idiosincrasia sampedrana y a la vez confirmó el respaldo popular de la obra, sin duda, la manifestación más importante de su proceso de validación social.

En el aspecto museográfico fue crucial contar con la cooperación del Archivo General de la Nación y el Museo de Arte de Lima, instituciones que pusieron a disposición sin costo alguno el uso de las imágenes de sus archivos para el desarrollo de las infografías.

El valor de todos estos aportes significó un desembolso efectivo de U\$ 25 mil dótares americanos. A esta suma se debe de agregar algunos gastos menudos cubiertos por la municipalidad, las sucesivas donaciones de personas naturales de la localidad así como la valoración de trabajos y servicios puestos a disposición del proyecto como pago por derecho de uso de imágenes, las que en su conjunto sobrepasan los U\$ 10 mil dólares americanos. Con estos aportes se afrontó el reto de poner en valor y acondicionar el inmueble en mención.

\section{Control del proyecto y montaje}

Este proyecto asumió como reto la coordinación en simultáneo de dos tareas en sendas localidades: el control de la obras de remodelación y refacción de la "Casa Museo" en San Pedro de Lloc y la provisión de los recursos museográficos necesarios para la exposición, tarea efectuada en Lima. El objetivo era que ambas labores culminaran al unísono, dejando así expedito el camino para el montaje de la exposición en todos los ambientes a intervenir en esta primera etapa.

Se debe indicar que en el momento en que el proyecto se encontraba en la etapa de sus estudios de factibilidad, en San Pedro de Lloc se fue formalizando espontáneamente un equipo de trabajo, que liderado por el Regidor Fredy Moncada $^{35}$, estuvo integrado por Jorge Carbajal, Jaime Gavidia y Jimmy Mejía ${ }^{36}$. El trabajo de este equipo, conformado por personas de gran estima popular en su localidad, fue fundamental a fin de que esta iniciativa fuera despertando una corriente de opinión favorable entre los otros miembros de la comunidad sampedrana. Mientras tanto en la ciudad de Lima, la responsabilidad del control del proyecto estuvo en manos del director del Museo Raimondi de Lima como del arquitecto Rodrigo Amorós. Cabe resaltar que la selección de imágenes, elaboración de textos y definición del estilo final de las infografías fue una etapa del trabajo especialmente ardua y extensa.

En el ínterin, se dieron viajes ida y vuelta entre los líderes de los equipos de Lima y San Pedro de Lloc, a fin de observar los avances en ambas localidades y establecer

${ }^{5}$ Regidor de Patrimonio Monumental e Histórico de la Municipalidad Provincial de Pacasmayo. Responsable del Área de Logística de Cementos Pacasmayo.e.mail: fmomcada@cpsaa.com.pe

Los que valgan verdades, eran los únicos que creían en el proyecto desde su inicio. 


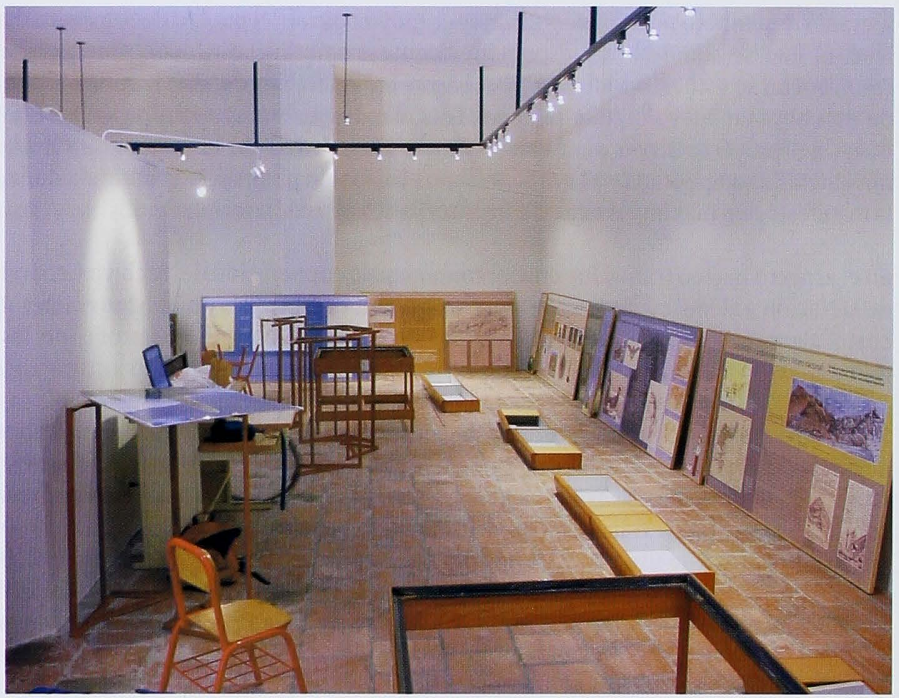

Foto 15

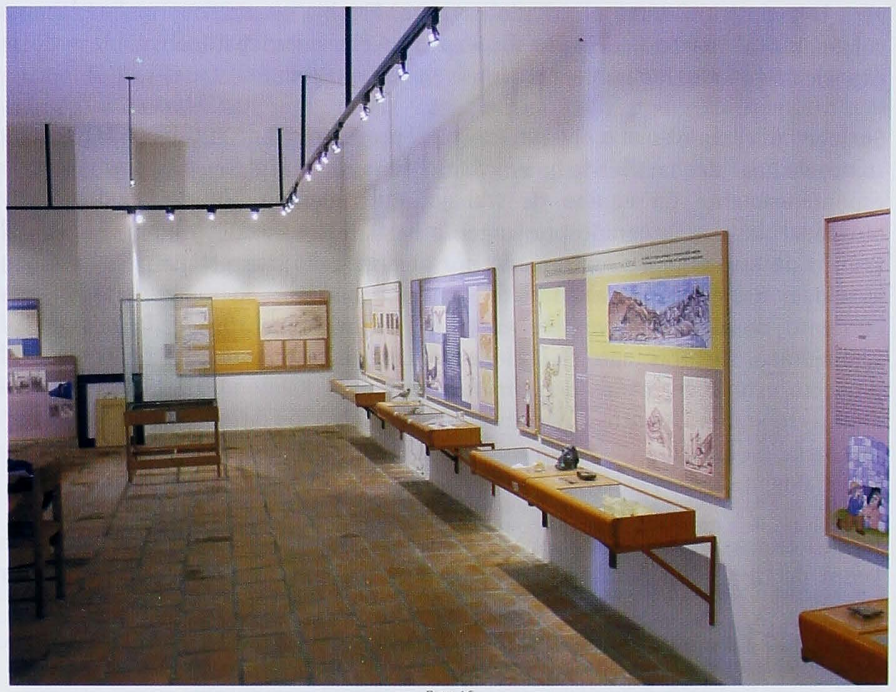




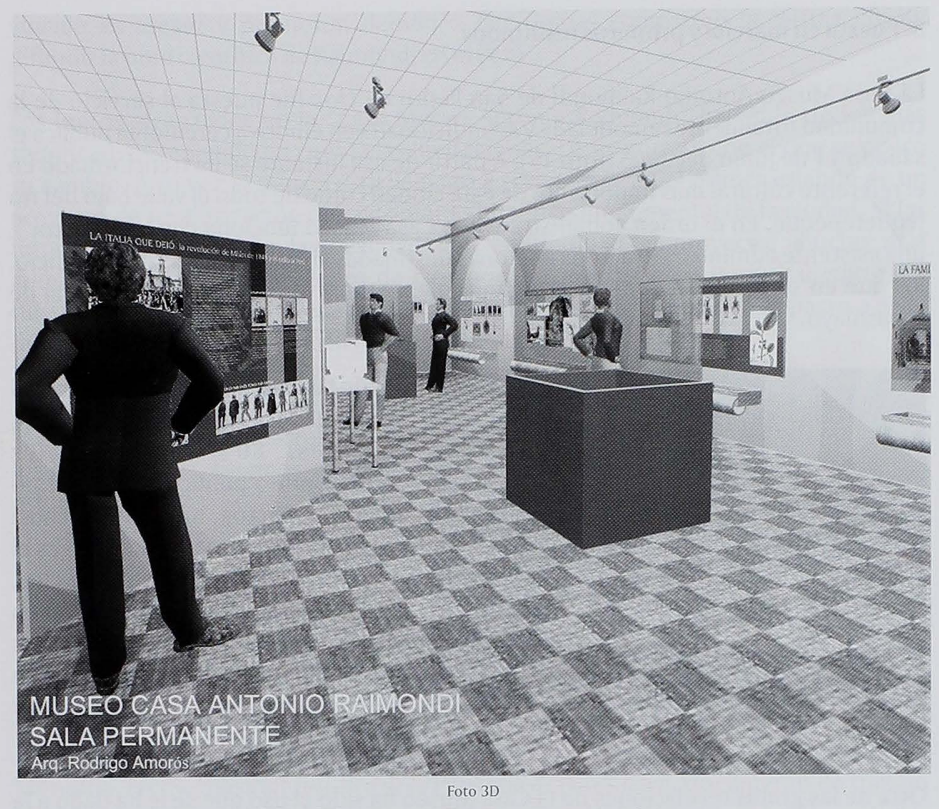

coordinaciones directas para afinar estrategias. En esta etapa se utilizaron todos los medios de comunicación disponibles (pe. teléfono, fax, email, encomiendas, etc.), los que en la fase final hicieron diaria la comunicación.

Todas las coordinaciones y esfuerzos culminaron tal cual lo planificado; de esta manera la totalidad de materiales, objetos y recursos museográficos llegaron a San Pedro de Lloc una semana antes de la exposición, quedando expeditos para su montaje en ambientes cuyas obras civiles estaban también terminadas ${ }^{37}$. Ello otorgó una adecuada holgura de tiempo a fin de resolver los detalles típicos de un montaje, solucionándose todos los problemas surgidos de manera satisfactoria y ante una creciente expectativa popular, la misma que era motivada por la prensa local.

De esta manera se llegó a la fecha programada sin ningún tipo de sobresalto, con todas las tareas realizadas y cumpliendo todo lo planificado (ver fotos 15 y 16; también 3D). Ello pone de manifiesto, una vez más, la importancia del trabajo en equipo y la delegación de funciones así como la organización de las prioridades y tareas por cumplir como parte de la ejecución de un programa debidamente planificado. Sin duda el aspecto más relevante de esta parte de nuestra labor fue comprobar el profesionalismo y compromiso asumido por el equipo de San Pedro de Lloc, sus autoridades y la población en general.

El traslado de los materiales se hizo en un camión de la empresa RANSA gracias al auspicio de la Empresa Cementos Pacasmayo. 


\section{Puesta en marcha y primeros resultados}

La Casa Museo Antonio Raimondi de San Pedro de Lloc fue puesta al servicio de la comunidad totalmente remodelada y acondicionada en emotiva ceremonia pública el sábado 11 de junio del 2005 (foto 17). A partir de ese instante se ha transformado en el referente cultural más importante de esta ciudad como de todo el valle bajo del río Jequetepeque. En el orden administrativo la Casa Museo funciona con un director ${ }^{38}$, una asistente administrativa y dos personas destinadas al mantenimiento del edificio, los que en su conjunto dependen orgánicamente de la Municipalidad Provincial de Pacasmayo.

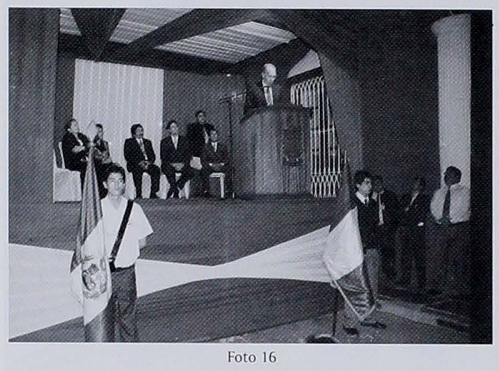

Desde su inauguración a la fecha ${ }^{39}$, el museo ha recibido casi mil visitantes pagantes, $80 \%$ de los cuales corresponde a público escolar ${ }^{40}$. Uno de los aspectos más interesantes desde el punto de vista turístico es el gran potencial de San Pedro de Lloc, al encontrarse a mitad de camino en la ruta entre Chiclayo y Trujillo, las dos ciudades de mayor crecimiento de flujo turístico del norte del Perú en los últimos años.

Otra de las gratas revelaciones de la Casa Museo ha sido el uso que se le ha dado a la sala temporal. En sus cuatro meses de funcionamiento ha sido el espacio de exhibición de tres muestras: la primera dedicada a las acuarelas botánicas de Raimondi (junio-julio), la segunda a la exposición de las obras de la pintora local María del Carmen Figueroa Razetto (agosto) y la tercera, en la modalidad de exposiciónventa, del pintor Jaime Vila Gutiérrez, de Pacasmayo (octubre y noviembre). De esta manera queda patente la importancia de la sala de exposición y la exitosa forma en que cumple su rol de espacio para los artistas y manifestaciones culturales de toda la provincia.

\section{Consideraciones finales}

El proyecto de remodelación y acondicionamiento museográfico de la Casa Museo Antonio Raimondi de la ciudad de San Pedro de Lloc culminó su primera etapa exitosamente. A la fecha este espacio tiene un perfil ascendente como referente cultural y principal destino turístico regional. Desde el punto de vista de su gestión, ella depende de la Municipalidad Provincial de Pacasmayo y del Director que ésta ha nombrado. El Museo Raimondi de Lima mantiene relación directa con la "Casa Museo", aunque no tiene injerencia directa en su administración; en ese sentido su

\footnotetext{
${ }^{38}$ Nombrado por la Municipalidad de Pacasmayo. Este cargo lo ejerce el Antropólogo Jorge Carbajal.

${ }^{39}$ Hasta septiembre del 2005.

${ }^{4}$ Estadística proporcionada por la Casa Museo Antonio Raimondi por los meses de Junio, Julio, Agosto y Septiembre.
} 
vínculo es asesor y promotor, debido a que ambas comparten la misma visión: difundir la obra científica de Raimondi en el Perú.

Los logros alcanzados en la "Casa Museo Antonio Raimondi" han sido de los más significativos teniendo en cuenta las limitaciones y presupuesto con el que se operó su cambio. A su vez el museo está llamado a convertirse en el primer eslabón de un proyecto de revalorización del patrimonio histórico monumental de la ciudad. Si las futuras autoridades de la localidad dan continuidad al proyecto, mucho más ambicioso e integral, San Pedro de Lloc podrá convertirse en la capital cultural y turística del valle de Jequetepeque, escenario que tendrá un positivo impacto a nivel de desarrollo económico y social de sus habitantes.

La primera prueba de este nuevo reto será la culminación de la segunda etapa de la "Casa Museo", cuyo desarrollo y ejecución corresponderán esta vez y en exclusiva a los sampedranos. Estamos seguros que el tiempo coronará con el éxito este nuevo esfuerzo.

\section{REFERENCIAS}

Moncada, Fredy. Potencial Turístico de la Provincia de Pacasmayo. Documento de trabajo elaborado por la regiduría de Patrimonio Monumental (Ms.) s/f.

Villacorta, Luis Felipe y Juan Carlos Burga. Guía para el manejo de pequeños museos. Elaborado por la Embajada de Italia en el Perú y el Goethe Institut. Lima. 2005.

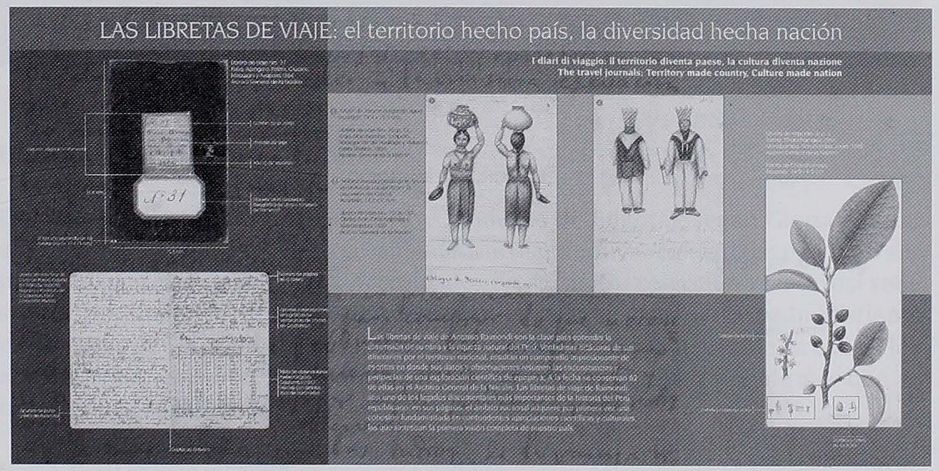

Foto de infografia 


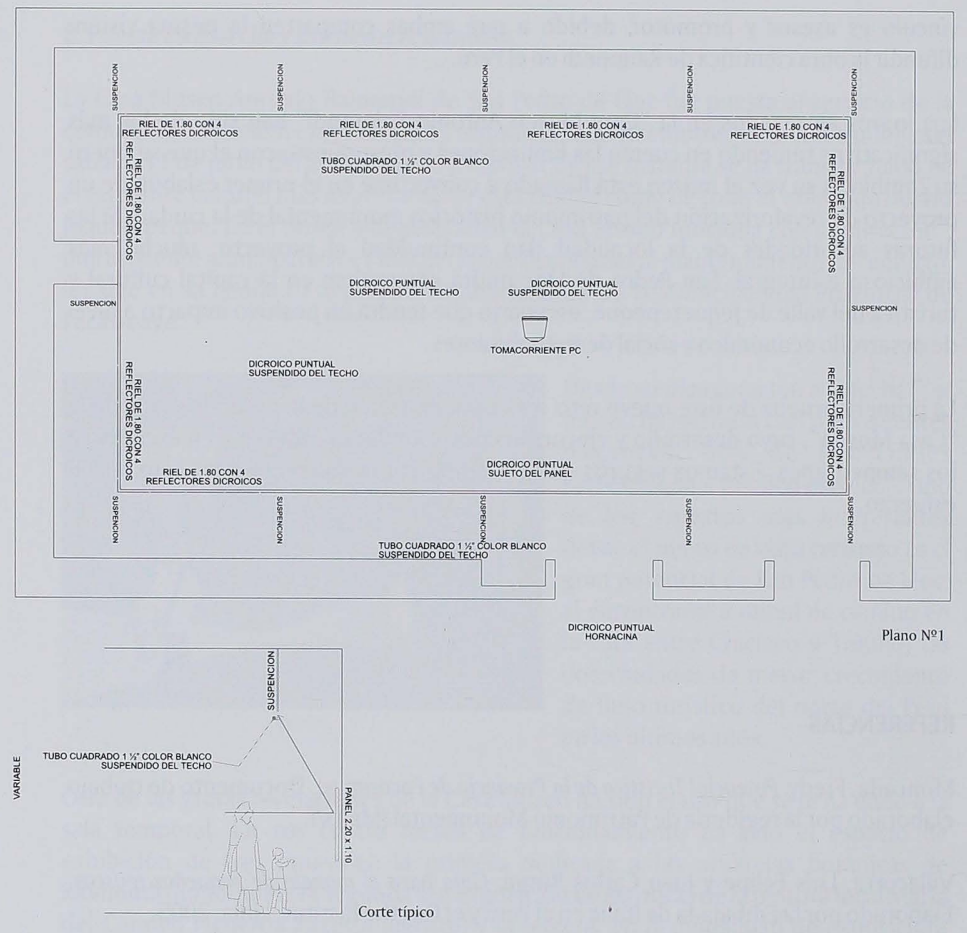

Plano N²

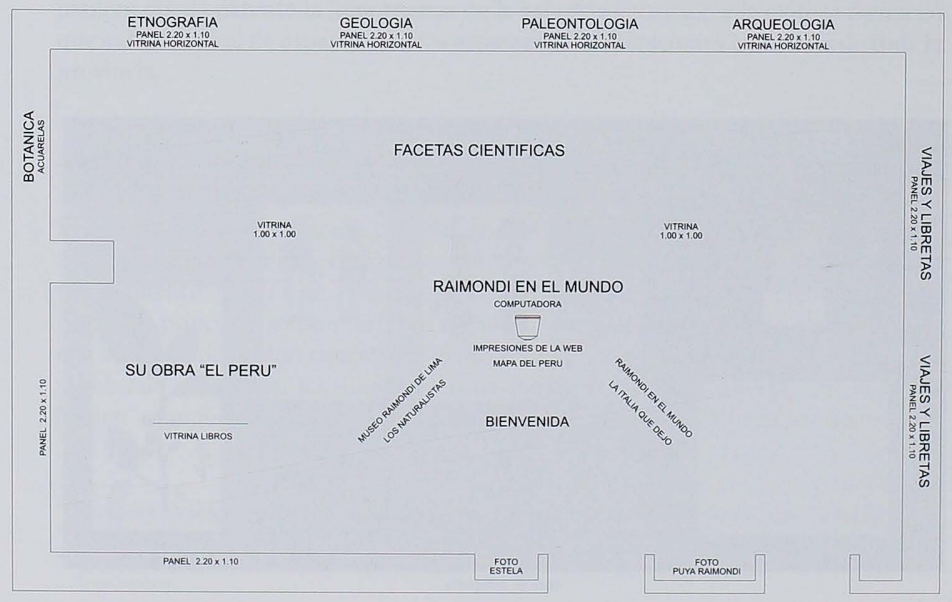

